\title{
College Students' Understanding of Fraction Operations
}

\author{
Brianna Bentley ${ }^{1}$, Michael J. Bossé ${ }^{1 *}$ \\ ${ }^{1}$ Appalachian State University, Boone, NC 28608, USA \\ *CORRESPONDENCE: $\square$ bossemj@appstate.edu
}

\begin{abstract}
This study investigates college students' understanding of arithmetic fraction operations as defined by the Common Core State Standards in grades three through six Mathematics. This study is meant to extend upon an extensive body of research regarding elementary and middle grades students' understanding of fraction operations and see if recognized erroneous thinking among younger students persist among college students. Among these misconceptions include: fraction equivalence, common denominators, the algorithm and the concept of division, whole number bias, and incorrectly applying fraction operations. The results of this study suggest that college students have the same misunderstandings and misconceptions as elementary students in regards to fraction operations.
\end{abstract}

Keywords: teaching and learning fraction, college students, fraction understanding

\section{INTRODUCTION}

A plethora of research over the decades has reported that elementary school students struggle with skills and concepts regarding fractions and fraction arithmetic. Types of misconceptions in student understanding of fractions have been cataloged in detail.

Since these misunderstandings often go unmitigated through a student's K-12 academic career, a growing body of research is demonstrating that college students also struggle with these concepts and skills. Unfortunately, the bulk of this research is based on whether or not students are able to correctly perform fraction arithmetic. Often missing is detailing the precise nature of the mathematical errors, misconceptions, and misunderstandings discoverable only through painstaking analysis of student work and communication regarding fractions and fraction operations.

To fill this gap, research is needed to investigate the nature of college students' misunderstandings and misconceptions regarding fractions and fraction operations. This paper seeks to partially address this concern.

\section{BACKGROUND LITERATURE}

To consider college students misunderstandings and misconceptions regarding fractions and fraction operations, a number of dimensions were researched including: the Common Core Standards for Mathematics; procedural versus conceptual understanding of fractions; why students have difficulties with fractions; areas of fraction misunderstandings; and effects of not understanding fractions. These are addressed below.

\section{Common Core}

Under the Common Core Standards for Mathematics, elementary students begin working with fractions as early as the third grade (Common Core Standards Initiative (CCSSI, 2010)). According to these standards,

\footnotetext{
Article History: Received 6 August $2018 \bullet$ Revised 15 August $2018 \bullet$ Accepted 20 August 2018

(C) 2018 The Author(s). Open Access terms of the Creative Commons Attribution 4.0 International License (http://creativecommons.org/licenses/by/4.0/) apply. The license permits unrestricted use, distribution, and reproduction in any medium, on the condition that users give exact credit to the original author(s) and the source, provide a link to the Creative Commons license, and indicate if they made any changes.
} 
in third grade, students begin exploring unit fractions, considering the part-whole definition of a fraction, using visual fraction models, and considering fraction equivalence.

In fourth grade, students extend their understanding of fractions by comparing fractions to a benchmark fraction and extend their understanding of fraction equivalence. Students also learn to add or subtract fractions with like denominators and solve word problems using this skill, to multiply a fraction by a whole number, and to compare decimal fractions.

In fifth grade, using common denominators, students are to perform fraction addition and subtraction with unlike denominators and solve word problems. Multiplication is extended to include multiplying a fraction by a fraction and solving real world problems involving multiplication of fractions and mixed numbers. Division of whole numbers by fractions, and vice versa, is explored and students are expected to be able to understand these quotients in context. This leads to an understanding of division of fractions by fractions in sixth grade.

Since college students have completed and passed all grades subsequent to these standards, theoretically they should have mastered these standards and possess an adequate foundation for fraction arithmetic. This study investigates this premise.

\section{Procedural versus Conceptual Understanding}

Conceptual knowledge is the ability to see interconnections among ideas and procedural knowledge is understanding processes and algorithms to produce results (Hallett, Nunes, \& Bryant, 2010). Research has perennially detailed elementary students' difficulties with fractions concepts (i.e. Braithwaite, Pyke, \& Siegler, 2017; Bulgar, 2003; Gabriel et al., 2013; Siegler et al., 2011; Valcke \& Desoete, 2014; Van Steenbrugge, Lesage, Tirosh, 2000). Students are regularly seen as possessing instrumental or procedural knowledge versus conceptual knowledge of fractions and operations, limiting their understanding of fractions (Byrnes \& Wasik, 1991; Kerslake, 1986; Rittle-Johnson, Siegler, \& Alibali, 2001). While Kerslake (1986) argues that students can solve some fraction problems using only procedural knowledge with limited conceptual understanding, Byrnes and Wasik (1991) note that the conceptual knowledge regarding fractions is a prerequisite for correctly performing fraction arithmetic. Somewhat resolving this debate, others suggest that conceptual and procedural knowledge grow and develop simultaneously, supporting each other as they develop (e.g., RittleJohnson et al., 2001).

Hallett et al. (2010) suggests that when learning fractions, some students rely more on procedural understanding, others rely more on conceptual understanding, and that individual differences can be recognized in how students combine conceptual and procedural knowledge. However, students who rely on conceptual knowledge may have an advantage when compared to their peers who rely on procedural knowledge. When students' conceptual knowledge of fractions is limited in comparison to their procedural knowledge or procedures are not understood conceptually, they may only develop a basic understanding of fractions (Van Steenbrugge et al., 2014) and are more likely to develop misunderstandings (Hallett et al., 2010; Resnick, 1982; Van Lehn, 1983). Bulgar (2003) argues children are taught algorithms about fractions with little contextual basis, and instead of focusing on student understanding, students are being asked to remember procedures and that this method of instruction does not lead to full understanding. Examination of the errors that children make suggests that children make many errors when they use a procedure without conceptual understanding (Kerslake, 1986).

Unfortunately, the explanation of the interplay of conceptual understanding and fraction arithmetic activity is insufficient in the literature. In other words, some students are able to correctly perform fraction arithmetic with limited conceptual understanding and others, through their limited understanding fail at performing arithmetic operations. Conversely, some students with seemingly solid conceptual understanding may be tripped up by teacher-taught techniques such as "keep-change-flip". Left undiscovered is what is the driving force between wrong thinking and improper arithmetic actions.

\section{Why Students Struggle with Fractions}

Research finds student difficulties with fractions originates from conflicts with natural numbers (e.g., Siegler et al., 2011; Stafylidou \& Vosniadou, 2004; Van Steenbrugge et al., 2014). Siegler et al. (2011) notes that children's knowledge of natural numbers serves as a conceptual barrier to their later learning about fractions. Stafylidou and Vosniadou (2004) expand upon this notion and state that fractions are problematic to students due to their inconsistency with the counting principles applicable to natural numbers, difference in fractional symbolic representation compared to natural numbers, counting-based algorithms cannot be used 
for ordering fractions, and operations differ when performed. Whole number bias results in errors and misconceptions since students prior conceptual understanding of numbers no longer holds (Van Steenbrugge et al., 2014). Students have to overcome this conflict between natural numbers and fractions in order to construct their understanding of fractions.

Some studies suggest that student difficulty with fractions arises from the fact that fractions comprise a multifaceted construct (e.g., Charalambous \& Pitta-Pantazi, 2007; Kieren, 1976; Van Steenbrugge et al., 2014). Questioning whether fractions comprise a single concept, Kieren (1976) suggests that fractions be thought of as interrelated concepts (i.e., ratio, operator, quotient, and measure, all later defined) and argues that understanding of fractions depends on developing an understanding of each of the subconstructs. It is important to note that Kieren did not initially consider part-whole as a sub-construct. Behr, Lesh, Post, and Silver (1983) suggests that the part-whole relationship comprise a fifth sub-construct. These five subconstructs are defined as (Charalambous \& Pitta-Pantazi, 2007; Van Steenbrugge, et al, 2014):

- The part-whole (PW) sub-construct defines a fraction as a comparison between the number of parts of the partitioned unit to the total number of parts in which the unit is partitioned.

- The ratio (Ra) sub-construct refers to the idea of a comparison between two quantities and is thus considered a comparative index rather than a number.

- The operator $(\mathrm{Op})$ sub-construct is the application of a function to a number, object, or set.

- The quotient $(\mathrm{Qu})$ sub-construct allows for any fraction to be seen as the result of a division situation. Unlike the part-whole sub-construct, two different measure units are considered.

- The measure (Me) sub-construct views fractions as numbers that can be ordered on a number line.

\section{Areas of Fraction Misunderstanding}

Misunderstandings regarding fractions are often classified as either procedural or conceptual. Procedural fraction misunderstanding includes whole number bias (WNB), incorrect fraction operation strategies (IFO), and division of two fractions (Div). Areas of conceptual misunderstandings include fraction equivalence (Eq) and abuses of the previously mentioned subconstructs (Braithwaite et al., 2017; Bulgar, 2003; Charalambous \& Pitta-Pantazi, 2007; Gabriel et al., 2013; Siegler et al., 2011; Tirosh, 2000; Van Steenbrugge et al., 2014).

Whole number bias involves performing the arithmetic operation on the numerators and denominators separately as if they were independent whole numbers (Braithwaite et al., 2017; Gabriel et al., 2013; Siegler et al., 2011; Van Steenbrugge et al., 2014). For example, $\frac{1}{3}+\frac{1}{4}=\frac{1+1}{3+4}=\frac{2}{7}$ leads to an incorrect answer.

Wrong fraction operation strategies involve a student treating the numerator or denominator incorrectly, but in a way that would be correct for a different fraction arithmetic operation (Braithwaite et al., 2017; Siegler et al., 2011; Van Steenbrugge et al., 2014). For example, students would generalize the ideas of common denominators in multiplication or division contexts, $\frac{3}{5} \cdot \frac{4}{5}=\frac{12}{5}$.

Division of fractions is often considered students' least understood and most difficult fraction arithmetic operation (Braithwaite et al., 2017; Bulgar, 2003; Tirosh, 2000). Tirosh (2000) refers to "algorithmically based mistakes" in respect to students incorrectly computing division expressions such as "flipping" the incorrect fraction or both. Since the algorithm for division of fractions is commonly not understood, this can lead to students forgetting steps or alternating the steps in a way that leads to errors.

The misunderstanding associated with fraction equivalence relates to the idea of adding dissimilar fractions, since similar fractions have to be found through the process of common denominators (Charalambous \& Pitta-Pantazi, 2007). The concept of fraction equivalence directly relates to why the process of common denominators is a valid method. Charalambous and Pitta-Pantazi (2007) also found the ratio subconstruct was directly related to students' understanding of equivalence of fractions, since finding equivalent fractions is closely related to proportions and finding equivalent ratios.

Charalambous and Pitta-Pantazi (2007) claim that the part-whole interpretation of fractions plays a significant role in developing the understanding of the other four subconstructs of fraction understanding and that the part-whole subconstruct should be considered necessary in developing an understanding of fractions. Van Steenbrugge et al. (2014) state that students are most successful with the part-whole subconstruct. 


\section{Effects of Not Understanding Fractions}

Elementary students' struggles with fraction knowledge and operations follow them through middle grades, high school, and college, with many learners never reaching proficiency in fraction arithmetic (Braithwaite et al., 2017; Gabriel et al., 2013; Yontz, Bossé, \& Sevier 2018). This affects both mathematical development and career aspirations. According to Siegler et al. (2012), fifth graders' fraction knowledge predicts their knowledge of algebra and mathematics achievement in the tenth grade. Moreover, mathematics achievement at age seven predicts socioeconomic status at age 42, even after controlling for the child's general intelligence, reading ability, and birth socioeconomic status (Ritchie \& Bates, 2013).

Fractions are among one of the most important topics discussed in mathematics classrooms and the understanding of fractions is critical to student's success in more advanced mathematics courses (Booth \& Newton, 2012; Braithwaite et al., 2017). Poor performance on problems associated with fraction understanding lead many students to be placed in collegiate developmental mathematics courses. Even in algebra, trigonometry, and calculus classes, students' difficulties with fractions inhibit their mathematical development.

Students pursuit of STEM fields at the collegiate level and in careers are often hindered by limited mathematical knowledge, including fundamental concepts regarding fractions (Wang, 2013). Wang's (2013) research suggests high school preparation in math and science plays a crucial role in developing students' interest in pursuing STEM fields and influencing entrance into STEM majors. By 2018, nine of the ten fastest growing occupations that require at least a bachelor's degree will depend on significant math or science training, and many science and engineering occupations are predicted to grow faster than the average rate for all occupations (Lacey \& Wright, 2009; National Science Board, 2010). Unfortunately, student interest in STEM fields is not consistent with the demand of the changing workforce (Wang, 2013). With mathematics achievement and math self-efficacy beliefs being major factors in student interest in STEM fields, it is imperative to develop students' confidence and understanding of mathematics topics, including fractions.

\section{METHODOLOGY}

\section{Participants}

Participants for this study included students of various majors at a medium sized university in southeastern United States. While the research opportunity was advertised globally to all students, fifty students volunteered for the study and eight students were randomly selected to participate. The research work was not connected to any class that the students were taking. Demographic information including class level and declared major are provided with the reported transcripts.

\section{Task}

Participants were given up to 60 minutes to complete both the research task and participate in some remedial discussions regarding the understanding of fractions and fraction arithmetic. The task included performing four arithmetic operations on fractions and explaining their work:

$$
\frac{2}{3}+\frac{5}{4} \quad \frac{11}{4}-\frac{4}{3} \quad \frac{3}{5} \times \frac{6}{4} \quad \frac{15}{4} \div \frac{2}{3}
$$

The problems were selected to cover the four operations of addition, subtraction, multiplication, and division, with each expression not including common denominators. It was anticipated that, through the work and explanations provided by the participants, these four examples would be sufficient to ascertain student understanding regarding fractions and fraction arithmetic. In addition to paper and pencil, participants were provided a number of manipulatives in order to either perform the arithmetic or explain their reasoning for such. Directions for the tasks stated:

For each of the following problems involving fractions, perform the arithmetic operation (i.e., ,,$+- \times$, and $\div$ ). Please explain all of your work and thoughts out loud as thoroughly as possible. A researcher may ask clarifying questions to see what you think.

After completing the research task with no questions or comments from the researchers, the participants were asked probing questions to delve deeply into their understandings and misunderstandings regarding fractions and fraction arithmetic. This resulted in much information which could not have been captured from the written mathematical work alone. Additionally, as will be later seen, student participants also experienced 
instructional intervention through which to (a) glean even further insight into their understanding and (b) assist them to leave possessing a more complete knowledge of fraction arithmetic.

\section{Data Collection and Analysis}

Participants agreed to be video-recorded in an interview session of up to 30 minutes. A task-based interview design (Goldin, 2000) was used through which to observe, record, and analyze student thoughts and actions. The videos were transcribed by one of the researchers. Two researchers then independently analyzed and performed open coding on the transcripts to determine themes and categories within the student work and articulations (Bogden \& Biklen, 2003; Creswell, 2003). Among numerous other dimensions noticed in the data was a distinction between students' computational work and their ability to articulate the reasoning behind the work.

The data was coded in the following manner. Transcripts were coded with WNB, IFO, or Div if participants demonstrated misunderstandings associated with those concepts. Notably, these codes connoted that the student interacted with the associated mathematics through procedural rather than conceptual understanding. In respect to conceptual understanding, the codes Eq, PW, Ra, Op, Qu, or Me were assigned when participants exhibited correct understanding of these constructs and $\underline{\mathrm{Eq}}, \underline{\mathrm{PW}}, \underline{\mathrm{Ra}}, \underline{\mathrm{Op}}, \underline{\mathrm{Qu}}$, or $\underline{\mathrm{Me}}$ were assigned when they exhibited incorrect understanding. Notably, $\underline{\mathrm{Eq}}, \underline{\mathrm{PW}}, \underline{\mathrm{Ra}}, \underline{\mathrm{Op}}, \underline{\mathrm{Qu}}$, and $\underline{\mathrm{Me}}$ can be interpreted as lacking conceptual understanding in these constructs or, almost synonymously, as demonstrating procedural understanding. Employing these codes, both researchers independently coded the transcripts. Then, to ensure validity of the coding structures, the researchers together compared and contrasted results using check-coding (Miles \& Huberman, 1994) to clarify thinking, sharpen code definitions, and reach consensus (Strauss \& Corbin, 1990). This led to the final iteration of coded transcripts which were used to analyze and synthesize findings.

\section{FINDINGS}

Notably, the following transcripts are very brief excerpts from much lengthier transcripts. Transcripts are from after the participants independently completed the four problems and during the interview session with the researcher. Each set of transcripts includes participant demographic information regarding class level and major field of study.

Student 1 (S1): Female, Freshman, Nursing major.

[Student 1 correctly performed the addition and subtraction problems. However, on the multiplication problem, she performed $\frac{3}{5} \times \frac{6}{4}=\left(\frac{3}{5} \cdot \frac{4}{4}\right) \times\left(\frac{6}{4} \cdot \frac{5}{5}\right)=\frac{12}{20} \cdot \frac{30}{20}=\frac{360}{400}[\mathrm{IFO}]$, and on the division problem, she performed $\frac{15}{4} \div \frac{2}{3}=\left(\frac{15}{4} \cdot \frac{3}{3}\right) \div\left(\frac{2}{3} \cdot \frac{4}{4}\right)=\frac{45}{12} \div \frac{8}{12}$ [IFO], became confused, and halted her work.]

S1: I just want to put everything in the common form; they both have the same denominators. That seems logical for the first one, but all the other ones seemed different. For subtracting and adding, I feel like that's ok; but these two, multiplying and dividing, I don't think that's right. I know that you can't do the addition without common denominators. You want to have it in the same whole number in the end. Right?... You could probably do it a different way, I just forget the other way to do it. You can like cross multiply or something. [IFO] I forget.

Overall, Student 1 had a vague understanding regarding the need for common denominators in addition and subtraction problems, but she did not know when and how to use them and could not articulate why common denominators were needed other than that they made the arithmetic easier. She generalized the idea of common denominators to the multiplication and division problems. She found common denominators and applied the operation to the numerators and kept the common denominator. In additional transcripts, she remembered the phrase "keep-change-flip" in respect to fraction division, but did not remember the process and when and how to apply it. [Div] Her misunderstanding of common denominators [IFO] and vague remembrance of fraction arithmetic caused her to incorrectly perform the multiplication and division problems and caused confusion when she was asked specific questions. 
Student 2: Male, Senior, English major.

[Student 2 correctly completed the addition, subtraction, and multiplication problems and was able to explain his use of arithmetic procedures. [Eq, PW, Op, Qu] For the division problem, he remembered the words "keep-change-flip" to do the division problem. When the researcher asked how he knew that was a valid method, he said that he knew that "keepchange-flip" was correct because that is what he had been taught and it worked. [Div] He never wondered why it was valid.]

Student 2 was able to correctly perform all the operations and correctly explain the processes he used. But he could not explain the underlying concepts regarding fraction division.

Student 3: Female, Senior, Biology major.

[Student 3 quickly and correctly completed all the arithmetic problems. After which, the researcher began inquiring about why she used her chosen techniques.]

R: When you worked on the addition problem, you converted the two fractions each into an equivalent fraction. You multiplied the $\frac{2}{3}$ by something and you multiplied the $\frac{5}{4}$ by something; but they were different somethings?

S3: Yes. So, the $\frac{2}{3}$ was multiplied by 4 and the $\frac{5}{4}$ was multiplied by 3 . [Eq]

R: A minute ago you told me that the $\frac{2}{3}$ was multiplied by 4 over 4 .

S3: It wouldn't be 4 over 4 because that would be 1. [WNB] That makes sense, right?

R: You said you multiplied the top and the bottom by 4 .

S3: Right, but that doesn't necessarily mean that would be 4 over 4 [Eq] because we know 4 over 4 is equal to 1 . [PW, Eq] So, to multiply, I would have to multiply the numerator and denominator by 4 separately. [Eq, PW] If I'm looking at the number 2 as just being 2 [WNB], I can multiply that by 4 , and then if I'm looking at $\frac{1}{3}[\mathrm{PW}]$ as being divided by 4 [WNB, Op]. So that could make it a 4 over 4 . But then, if I'm dividing 1 over 3 by 4 over 4 or by 1 over 4 then I would multiply by the reciprocal. No. Because then that would give me 4 over 3. Ok, this is a hard question. All I really know is that I can do it.

Student 3 quickly performed all of the operations correctly but was unable to explain the processes involved [Eq, PW, Ra, Op]. She saw the connection in common denominators to equivalent fractions. However, she recognized multiplying the numerator and denominator separately and did not make the connection that she was actually multiplying the fraction by 1 . [Eq] Overall, while her arithmetic skills were perfect, her understanding beyond the purely procedural was severely lacking.

Student 4: Female, Freshman, Exercise Science major.

[After getting correct answers on all problems, Student 4 reconsiders her work regarding multiplication of fractions. She second guesses her work and decides to redo the multiplication problem, this time starting with finding common denominators [IFO] and then multiplying across the numerators and retaining the common denominator.]

S4: So, this would be 12 times 30 , and writes $\frac{12}{20} \cdot \frac{30}{20}=\frac{360}{20}=\frac{36}{2}=18[$ IFO, Eq]).

R: So, you multiplied across the numerator. But then you kept the common denominator.

S4: Because, if it's the same denominator, you just multiply the numerator. [IFO]

In additional transcripts, Student 4 was initially able to correctly perform all the operations. However, when asked to explain the processes she used, she often could not explain processes and began to doubt her work, resulting in numerous mistakes and misconceptions. While she recognized that the use of common denominators in addition was simply an application of multiplying the fractions by 1 , she displayed incomplete 
understanding of this process in two ways. First, she saw this multiplication as little more than "doing the same thing on the top and the bottom". [WNB] For instance, she stated that when a fraction is added to a fraction equal to 1 (e.g., $\frac{a}{a}$ ) it was appropriate to simply add across the numerators and denominators (e.g., $\frac{2}{3}+$ $\left.\frac{a}{a}=\frac{2+a}{3+a}\right)$. [Eq] But, after only a quick moment of contemplating what she said, she changed her mind and stated that this was not correct and that it only works for multiplication. When explaining multiplication, she became confused regarding keeping the common denominator or multiplying across the denominators. [IFO] While she correctly explained the "keep-change-flip" procedure, she had no understanding as to why the process was valid. [Div] In respect to the division problem, she struggled with the concept of the fractional denominator being the contextualized "whole". [므, $\underline{\mathrm{Qu}}]$

Student 5: Female, Freshman, Computer Science major

[After completing the problems with many errors, the interview revealed numerous misconceptions. For the addition problem, Student 5 performed: $\frac{2}{3}+\frac{3}{4}=\frac{2}{3} \cdot \frac{4}{4}+\frac{3}{4} \cdot \frac{3}{3}=\frac{8}{12}+$ $\left.\frac{9}{12}=\frac{17}{144} \cdot\right][\mathrm{IFO}, \mathrm{Eq}]$

S5: You're supposed to get common denominators and then do the parenthesis, like the multiply, add, subtract, or divide thing. [IFO]

[For the subtraction problem, the student performed: $\frac{11}{4}-\frac{4}{3}=\frac{11}{4} \cdot \frac{3}{3}-\frac{4}{3} \cdot \frac{4}{4}=\frac{33}{12}-\frac{16}{12}=\frac{17}{12}$ ]

S5: I think that this is wrong. But I can't do what I want.

R: What do you want to do?

S5: I think that I should do 33-16 on the top and 12-12 on the bottom. [WNB] But that would give me 0 on the bottom. We can't have a 0 in the bottom. So, I kept the 12. [Qu]

R: So, you only kept the 12 because you couldn't have a 0 ?

S5: Yes

R: On the multiplication problem, you just multiplied across the numerators and denominators. Why?

S5: Because it just says multiply.

R: If you multiply straight across because it says multiply, then why don't you just add or subtract straight across when those are the operations?

S5: I don't know.

[For the division problem, the student performed: $\frac{15}{4} \div \frac{2}{3}=\frac{15}{4} \cdot \frac{3}{2}=\frac{45}{8}$.]

Most of Student 5's misunderstandings seemed connected to the notion, purpose, and appropriate use of common denominators [Eq, IFO] and a failure to recognize that the underlying process associated with rewriting fractions into possessing common denominators is multiplying by one. This led the majority of the remaining discussions. While she was able to explain the process of finding the common denominators, she had no understanding of why to multiply by $\frac{a}{a}$ or $\frac{b}{b}$. $[\underline{\mathrm{Eq}}, \underline{\mathrm{PW}}]$ She multiplied the common denominators in the addition problem [IFO], left the common denominator in the subtraction problem (because $\frac{17}{0}$ would be wrong) [Qu], multiplied the denominators in the multiplication problem "because of the multiplication sign" [WNB], and used "keep-change-flip" in the division problem and then multiplied across the denominators. She demonstrated no consistency of ideas or techniques. 
Student 6: Female, Senior, Psychology and Studio Arts major.

[Student 6 completes the addition and subtraction problems. Completing the multiplication problem, she cross multiplies [IFO], considers this for a moment, and then correctly redoes the example multiplying across the numerators and denominators. [Op] She then correctly completes the division problem. After completing the problems, she confessed that she had some difficulty on the multiplication and division examples and repeatedly denoted the fraction operation processes as simply "remembering the right tricks." She is unable to explain why any of the processes work or are valid. [Eq, PW, Ra, Op]]

Student 6 correctly completes all the problems using the "tricks" she remembers, but does not recognize, the mathematical justifications supporting these techniques. Not being able to immediately recollect the correct algorithm caused her to initially make an error on the multiplication problem - only to quickly correct it. While she interacts procedurally with the concepts, she seems only inches away from conceptual understanding. For instance, upon being asked to explain how she determined a common denominator and equivalent fractions in the context of addition, the probing questions immediately lead her to understand that she was multiplying by a fraction in the form of $\frac{a}{a}$ which was equal to 1 .

Student 7: Female, Senior, Psychology and Philosophy major.

[Student writes $\frac{3}{5} \times \frac{6}{4}=\frac{3}{5} \times \frac{4}{6}$ [IFO], but does not complete the calculations. Then she writes $\frac{15}{4} \div \frac{2}{3}=\frac{\frac{15}{4}}{\frac{2}{3}}$ [Div, Ra], stops, and writes $\frac{15}{4} \div \frac{2}{3}=\frac{15}{4} \times \frac{3}{2}=\frac{45}{8}$. She then returns to the multiplication problem and writes $\frac{3}{5} \times \frac{6}{4}=\frac{18}{20}=\frac{9}{10}$.]

R: I like your vocabulary, that you're saying the "whole". So let's go back to your division problem. What is the contextualized whole in this problem?

S7: The denominator in a single fraction is what determines the whole. [Div] So, in the division problem, the denominator should be the whole. But here you are comparing two different fractions. $\frac{15}{4} \div \frac{4}{3}$ has two wholes. [Ra, Op] The whole should be the denominators because those are what you're comparing, but there are two different denominators. Oddly, this $\frac{2}{3}$ is the whole. But that doesn't make sense. [WNB] But neither does 3 being the whole.

R: Could you give me a real-world situation where maybe $\frac{2}{3}$ could be the whole?

S7: Yes, but also having a fraction as your whole just feels wrong. [WNB] Cause then a whole one is a whole, like a full thing. But you know a fraction typically is not. [Ra] It's just part of the whole, which is why I feel like the fraction can't be a whole. [PW] Except that maybe it can.

Student 7 initially "flips" the second fraction in the multiplication example [IFO], but then remembered that to be the process for division [Div]. Once completing the division example, she realizes that she simply multiplied across the numerators and denominators [WMB] and uses that idea to return to correctly complete the multiplication problem. Through additional transcripts, she made several mistakes in the "simplifying" stages of most of the problems. Her work indicated a lack of conceptual understanding that the rewriting of a fraction into an equivalent form included the step of multiplying by $\frac{a}{a}=1$. While she seemed to understand that $\frac{2}{3}=\frac{8}{12}[\mathrm{Eq}]$, she did not understand that $\frac{2}{3}=\frac{2}{3} \cdot 1=\frac{2}{3} \cdot \frac{4}{4}=\frac{8}{12}[\mathrm{Eq}]$. In attempting to generate fractions with common denominators, she procedurally used the notation $4\left(\frac{2}{3}\right)=\frac{8}{12}$ to represent $\frac{4}{4} \cdot \frac{2}{3}$. [Qu]

She also struggled to understand the concept of the contextualized whole and wrestled with accepting that a fraction could be the contextualized whole in a particular expression. [Div] During the discussion with the researcher, Student 7 provided understanding that $\frac{2}{3}$ could be the contextualized whole in a real-world problem (e.g., $\frac{2}{3}$ of a pizza as a whole serving). [PW] However, she was confused when attempting to explain that, for $\frac{15}{4} \div \frac{2}{3}=\frac{45}{8}$, the contextualized whole for the problem is $\frac{2}{3}$ and that $\frac{45}{8} \cdot \frac{2}{3}=\frac{15}{4}[\underline{\mathrm{PW}}$, Div] 
Student 8: Female, Freshman, English major.

[Student 8 fully explains common denominators and why they are necessary as well as the connection to equivalent fractions and multiplying by $\frac{a}{a}=1$. [Eq, PW]]

R: Can you explain why changing a division problem to multiplication might work?

S8: Hmm. Because $\frac{2}{3}$ is already division $[\mathrm{Qu}]$ and you have one other division sign too, so it's technically dividing twice and you're kind of dividing something that's already a division [Div, Op] and then that's going to end up being multiplication. It's like your taking something and you're breaking it up into a fraction, which ends up giving you like a larger number, like I just... I've never really thought about it. I just know that, when you divide by something less than 1, you end up with a larger number [Me]. Because you're kind of breaking it up into something. When you break it up, when you divide by something larger than 1 you end up with a smaller number and when it's the opposite when you're dividing by something less than 1 [Div] you end up with a greater number. Wait, division of a division becomes multiplication just like subtracting a negative makes a positive. [IFO]

Overall, Student 8 demonstrates an excellent understanding of fractions and is able to communicate her thinking about fractions very well. However, she demonstrates confusion regarding fraction division. [Div] She seemed to confuse the idea of "subtracting a negative makes a positive" and applied this to division stating that dividing by a fraction means multiplication. [IFO] Thus, her communication reveals that she considered fraction division procedurally rather than conceptually. She also struggled with the concept of the contextualized whole in fraction division [Div], insisting that the contextualized whole in a division problem would necessarily be a whole number [WNB].

\section{Initial Summary}

Summarily:

- Student 1 demonstrated procedural understanding through IFO and Div constructs.

- Student 2 performed operations correctly but demonstrated procedural understanding through the Div construct.

- Student 3 demonstrated only a few instances of conceptual understanding through Eq and PW concepts, but numerous instances of procedural understanding through WNB, $\underline{\mathrm{Eq}}, \underline{\mathrm{PW}}$, and $\underline{\mathrm{Op}}$.

- Student 4 demonstrated no examples of conceptual understanding and numerous examples of procedural understanding through the constructs WNB, IFO, $\underline{\mathrm{Eq}}$, Div, $\underline{\mathrm{Ra}}$, and $\underline{\mathrm{Qu}}$.

- Student 5 exhibited no examples of conceptual understanding and numerous examples of procedural understanding through the WNB, IFO, $\underline{\mathrm{Eq}}, \underline{\mathrm{PW}}$, and $\underline{\mathrm{Qu}}$, constructs.

- Student 6 demonstrated only one example of conceptual understanding [Op] and numerous examples of procedural understanding through IFO, Eq, $\underline{\mathrm{PW}}, \underline{\mathrm{Ra}}$, and $\underline{\mathrm{Op}}$.

- Student 7 exhibited only one example of conceptual understanding [Eq] and numerous examples of procedural understanding: WNB, IFO, Div, Eq, $\underline{\mathrm{PW}}, \underline{\mathrm{Ra}}$, and $\underline{\mathrm{Op}}$.

- Student 8 demonstrated both conceptual understanding [Eq, PW, Op, Qu, and Me] and procedural understanding [Div and IFO].

Additional initial summaries of the findings are provided through two stages: prior to and following instructional intervention.

Prior to Intervention. The most common observations among participant work can be simplified to:

- While only a couple participants were able to correctly perform the four operation examples, none of the participants could fully explain why their algorithms worked or were mathematically valid.

- Most students remembered either the appropriate algorithms to perform the operations or portions of those algorithms.

- Participants commonly misremembered when they needed to use common denominators and attempted to apply common denominators in incorrect situations. 
- Almost no students recognized that multiplying by $\frac{a}{a}$ was equivalent to multiplying by 1 and that the purpose was to produce a different yet equivalent expression.

- While some students understood the technique of rewriting a division operation to multiplication of the inverse, no student could provide an explanation of how this may be mathematically valid.

- No student understood concepts regarding fraction division including that the contextualized whole of a problem need not be a natural number and what division by a fraction means.

Summarily while these students demonstrated procedural knowledge regarding fraction operations, they had very limited conceptual understanding of what they were doing.

During and After Intervention. Since this research activity was also an opportunity through which participants could learn more about fraction operations and computations, near the end of the interview session, one of the researchers used inquiry-based instructional techniques to lead the participant to deeper understanding of the investigated concepts. It was anticipated that more data could be gleaned regarding student understanding after this brief intervention. Although the remedial instruction was based on the individual participant's needs, understanding, and misunderstandings, the topics generally covered the following:

1. Investigating that, since $\frac{b}{b}=\frac{d}{d}=1$ and $\frac{a}{b} \cdot \frac{d}{d}=\frac{a d}{b d}$, it can be seen that $\frac{a}{b} \pm \frac{c}{d}=\frac{a}{b} \cdot \frac{d}{d} \pm \frac{c}{d} \cdot \frac{b}{b}=\frac{a d}{b d} \pm \frac{b c}{b d}=$ $\frac{a d \pm b c}{b d}$.

2. Noticing that, since $\frac{a}{b} \div \frac{c}{d}=\frac{\frac{a}{b}}{\frac{c}{d}}=\frac{\frac{a}{b}}{\frac{c}{d}} \cdot 1=\frac{\frac{a}{b}}{\frac{c}{d}} \cdot \frac{\frac{d}{c}}{\frac{d}{c}}=\frac{\frac{a d}{b c}}{\frac{c d}{c d}}=\frac{\frac{a d}{b c}}{1}=\frac{a d}{b c}$ and $\frac{a}{b} \div \frac{c}{d}=\frac{\frac{a}{b}}{\frac{b}{d}}=\frac{\frac{a}{b}}{\frac{b}{d}} \cdot 1=\frac{\frac{a}{b}}{\frac{c}{d}} \cdot \frac{b d}{b d}=\frac{\frac{a b d}{b}}{\frac{b c d}{d}}=\frac{\frac{a d}{1}}{\frac{b c}{1}}=\frac{a d}{b c}$ come to the same result as $\frac{a}{b} \div \frac{c}{d}=\frac{a}{b} \cdot \frac{d}{c}=\frac{a d}{b c}$, the latter must be mathematically valid.

3. A diagrammatic area model was used to demonstrate the product of two fractions.

4. Fraction bars (both physical and diagrammatic) and number line partitioning were used to demonstrate division by a fraction including the notion that, if $\frac{a}{b} \div \frac{c}{d}=e \frac{f}{g}$, this means that $\left(e \cdot \frac{c}{d}\right)+$ $\left(\frac{f}{g} \cdot \frac{c}{d}\right)=\frac{a}{b}$. Thus, the remainder $\frac{f}{g}$ does not simply mean the value $\frac{f}{g}$, it means $\frac{f}{g}$ of the divisor, or contextualized whole, $\frac{c}{d}$.

These interventions led most of the participants to deeper conceptual understanding of the fraction operations addressed in this study. However, possibly more importantly, it provided an additional window of opportunity to communicate with and observe the ideas articulated by the participants. This opportunity led to more nuanced understanding of some concepts held by the participants. These are addressed in the following discussions.

\section{DISCUSSION}

Through this study, the researchers found that college students share similar misconceptions regarding fraction arithmetic with elementary students. However, the reasoning of college students was more readily discerned because they were more articulate in their descriptions of their thought processes than are most elementary school children. This was found to be invaluable in analyzing and understanding their thinking processes.

As previously stated, the findings above are reported in a rather simplistic manner. Deeper analysis of student work and communication led to further understanding of processes employed and understood when these participants performed arithmetic operations on fractions. These findings are provided below and separated by the fraction arithmetic operation considered.

\section{Multiplication}

Most student participants could algorithmically perform fraction multiplication. However, only one student could explain such using an area model. Some students recognized that $\frac{2}{3} \times \frac{4}{3}$ would produce a product less than $\frac{4}{3}$ and greater than $\frac{2}{3}$, based singularly on the notion that $\frac{2}{3}<1<\frac{4}{3}$. Thus, rather than understanding the meaning of fraction multiplication or being able to model it in some manner, the students singularly understood that, for positive valued fractions, a factor less than 1 produced a product less than the other factor 
and a factor greater than 1 produced a product greater than the remaining factor. Although most students correctly performed fraction multiplication, they demonstrated very limited conceptual understanding of their processes.

\section{Division}

While only some of the participants could perform the fraction division operation, observations revealed that none could explain why "invert-and-multiply" or "keep-change-flip" was mathematically valid. Two particular concepts seemed commonly lacking. First, students struggled with the notion of the contextualized whole (e.g., for $\frac{15}{4} \div \frac{2}{3}=\frac{\frac{15}{4}}{\frac{2}{3}}, \frac{2}{3}$ would be the whole contextualized in this problem). When mentioned that $\frac{2}{3}$ of a pizza could be a "whole serving", students recognized that a fraction could be the contextualized whole in a particular real-world situation. However, they struggled to apply this idea in fraction division segregated from real world applications.

Second, students were unable to articulate meaning to the fraction division. They did not recognize that $\frac{15}{4} \div \frac{2}{3}$ meant “ $\frac{2}{3}$ divided into $\frac{15}{4}$, or even “ $\frac{2}{3}$ goes into $\frac{15}{4}$,. Notably, they interpreted $\frac{15}{4} \div \frac{2}{3}$ to mean $\frac{15}{4} \times \frac{3}{2}$. Students were then shown the meaning of fraction division through repeated subtraction using fraction bars. For instance, a length of $\frac{15}{4}=3 \frac{3}{4}$ was laid out on the table. Below it was aligned pieces of length $\frac{2}{3}$. Students immediately recognized that $\frac{2}{3}$ went into $3 \frac{3}{4}$ five times with $\frac{5}{12}$ of the $3 \frac{3}{4}$ yet unaccounted for. When asked “ $\frac{2}{3}$ times what is $\frac{5}{12}$, some wrote $\frac{2}{3} \times x=\frac{5}{12}$ and solved $x=\frac{5}{12} \times \frac{3}{2}=\frac{5}{8}$. Some came to understand that $\frac{15}{4} \div \frac{2}{3}=5 \frac{5}{8}$. However, when asked "You have an answer of $5 \frac{5}{8}$, but $5 \frac{5}{8}$ what?" some students were unable to recognize that it meant $5 \frac{5}{8}$ of the conceptual whole, $\frac{2}{3}$.

When they were asked to perform the operation $5 \frac{5}{8} \times \frac{2}{3}$, most students were quite able to find the product $\frac{15}{4}$. When pointed out, they were quite surprised to see that $\frac{15}{4}$ was the original dividend of the division problem. When contextualized with integers, they recognized that $\mathrm{a} \div \mathrm{b}=\mathrm{c} \Leftrightarrow \mathrm{a}=\mathrm{bc}$; however, only one student came to recognize that $\frac{15}{4} \div \frac{2}{3}=5 \frac{5}{8} \Leftrightarrow \frac{15}{4}=\left(5 \frac{5}{8}\right) \cdot \frac{2}{3}$.

\section{Addition and Subtraction}

An interesting finding arose regarding the least common denominator associated with addition and subtraction problems. It can be noticed that the process of rewriting fractional addends into addends with common denominators includes the process of fraction multiplication (i.e., $\frac{a}{b}+\frac{c}{d}=\frac{a}{b} \cdot \frac{d}{d}+\frac{c}{d} \cdot \frac{b}{b}$ ).

In this study, while most students were able to complete fraction multiplication, they failed to recognize the use of multiplication when finding common denominators for fractional addends; they recognized the process of rewriting fractions to share common denominators as something quite different from fraction multiplication. Students perceived rewriting fractions into common denominator form as a two-step process, as shown in Figure 1.

$$
\frac{a}{b} \mid \times c \text { Step 1 } \mid \times c \text { Step 2 }
$$

Figure 1. Two-step process of rewriting into common denominators

In Step 1, they considered the fraction $\frac{a}{b}$ and by what value, $c$, they would need to multiply $b$ in order to rewrite the fraction with a denominator common to the other fraction addend. In Step 2, they multiplied the numerator $a$ by the same value $c$. Notably, they perceived these two steps as distinct and sequential. This is further developed through the following notions.

First, students multiplied the numerator by $c$ because "whatever you do to the denominator you do to the numerator." When asked "Ok, so if you add a value to the denominator, do you add the same value to the numerator, and will this produce an equivalent expression?", most students initially responded that they believed it would. Thus, they were more focused on performing two similar steps than they were on multiplying the fractions. 
Second, when students were rewriting fractions into common denominators, some were asked, "So, you are multiplying by $c$ over $c$ ?" To which some responded, "No, that would be the same as multiplying by 1 , and if I multiply by 1 , I'll get the same thing" or "I am not multiplying by $c$ over $c$. I am multiplying by $c$ in the bottom and then by $c$ in the top, to do the same thing." This revealed important ideas in student reasoning:

1. Students perceived multiplication of fractions as distinct from this rewriting a fraction with a common denominator. While multiplication of fractions was perceived as a matter of multiplying simultaneously across numerators and denominators, constructing fractions with common denominators was recognized as "doing the same thing" after the step was determined through investigation of the denominator.

2. The sequencing of the multiplications in Step 1 from Step 2 denoted that students were not actually multiplying $\frac{a}{b}$ by $\frac{c}{c}$. Indeed, some students explicitly stated that this was not what they wanted to do. They did not want to multiply by " $c$ over $c$ "; they wanted to multiply by $c$ in the denominator and again in the numerator. Thus, either they (A) did not want to multiply by "c over $c$ " or (B) they did not recognize that, in essence, that was exactly what they were doing, or $(\mathrm{C})$ both $\mathrm{A}$ and $\mathrm{B}$.

3. Beyond not recognizing that they were multiplying $\frac{a}{b}$ by $\frac{c}{c}$, the students did not recognize that they were multiplying $\frac{a}{b}$ by 1 , thus maintaining the value of $\frac{a}{b}$. Most of the students were completely oblivious to the purpose of the process was to produce $\frac{a}{b}=\frac{a}{b} \cdot 1=\frac{a}{b} \cdot \frac{c}{c}=\frac{a c}{b c}$. And, when one student did recognize it, she indicated that this was NOT what she wished to do.

\section{IMPLICATION}

Numerous significant implications to the findings in this study are provided in this section. First, the students in this study may reveal that many students can adequately perform operations on fractions without the students possessing conceptual understanding of what they are doing. While being able to perform fraction operations is a positive result, it may be that lacking conceptual understanding will quell future potential mathematical development if not mitigated. This has implication for mathematics education in general. Since reform efforts dating back to the 1980s, there have been calls for greater emphasis in conceptual understanding in math learning (e.g., NCTM, 1989). It must be wondered how effective this has been.

Second, for the college students involved in this study, it seems that their misconceptions and reliance on procedural versus conceptual understanding are in many ways consistent with those held by elementary and middle grades students. This causes one to wonder how widespread this is among broader audiences of college students. This should be further investigated to determine the breakdown between instructional practices and fractional understanding. Additionally, it warrants investigation as to how the K-12 mathematics curriculum could be further redesigned to help students learn and retain conceptual concepts regarding fractions and fraction operations.

Third, college students' focus on procedural understanding of fractions and fraction operations may lead to limitations in mathematical ability and limit them in future career paths. This may further exacerbate the difficulty of recruiting college students into high-demand STEM fields.

Fourth, and possibly most importantly, the findings and discussion may shed light on how college students perform particular fraction operations and what they think when doing so. Particularly, the findings may indicate disconnected and fractured ideas regarding the operations of addition and subtraction, multiplication, and division.

Regarding addition and subtraction, students may perceive $\frac{a}{b} \times \frac{c}{c}$ differently when in the context of fraction multiplication rather than in the context of constructing fractions with like denominators. Indeed, these findings may imply that students do not understand that multiplication by $\frac{c}{c}$ is multiplication by 1 and intended to create a new fraction of equal value. The two-step process employed by the students of rewriting fractions into common denominators implies that students have limited conceptual understanding regarding this process. Rather students may only have the procedural understanding to "multiply the top by what they multiplied by in the bottom". This disconnect between multiplication and finding common denominators suggests that these ideas are not being taught or learned as the same process. From this finding it can be argued that, to help students better make connections between these processes and strengthen their conceptual understanding, fraction multiplication should be taught prior to fraction addition and subtraction. 
Regarding multiplication, the findings imply that students perform fraction multiplication algorithmically, with little understanding of what it means. Since fraction multiplication is central to the other fraction operations of addition, subtraction, and division, misunderstanding multiplication leads naturally to misunderstanding other fraction operations. This may mean that fraction multiplication should be taught and learned prior to fraction addition and subtraction.

Students seem to automatically rewrite division by a fraction into multiplication by the inverse that most of the concepts regarding division seem lost or hidden including the contextualized whole in the problem, the justification that verifies rewriting as a multiplication problem, and the actual meaning of division apart from an arithmetic algorithm. Furthermore, this may imply that, since students do not fully understand that a $\div$ $\mathrm{b}=\mathrm{c} \Leftrightarrow \mathrm{a}=\mathrm{bc}$, there may be many other fundamental concepts that they have not fully grasped. While the literature well documents that K-12 students struggle with division by fractions, it is also known that K-12 mathematics teachers similarly struggle with this concept (Ma, 1999). Altogether, this may imply that much work is yet needed in K-12 mathematics to solidify concepts associated with division.

Altogether, one far-reaching implication to this study is that the U.S. educational system may not be effective in the teaching and learning of fractions. This is not to cast blame on teachers, curricula, or students. Rather, in order to fix a problem, we must first recognize that one exists.

\section{CONCLUSIONS}

Our finding suggests that college level students have the same misunderstandings as elementary school students regarding fraction operations. While most of the participants in our study remembered "keep, change, flip" none could explain why this process was valid or even what they were doing when they used this process. Several students remembered the idea of common denominators and correctly applied them in the addition and subtraction problems, but some overgeneralized this process to every problem or did not know what to do once they had found common denominators. Overall, participant's procedural understanding far outweighed their conceptual understanding.

\section{Disclosure statement}

No potential conflict of interest was reported by the authors.

\section{Notes on contributors}

Brianna Bentley - Appalachian State University, Boone, NC 28608, USA.

Michael J. Bossé - Appalachian State University, Boone, NC 28608, USA.

\section{REFERENCES}

Behr, M., Lesh, R., Post, T., \& Silver, E. (1983). Rational number concepts. In R. Lesh \& M. Landau (Eds.), Acquisition of Mathematics Concepts and Processes, (pp. 91-125). New York, NY: Academic Press.

Bogdan, R. C., \& Biklen, S. K. (2003). Qualitative research for education: An introduction to theories and methods (4th ed.). Boston: Allyn and Bacon.

Booth, J. L., \& Newton, K. J. (2012). Fractions: Could they really be the gatekeeper's doorman? Contemporary Educational Psychology, 37(4), 247-253. https://doi.org/10.1016/j.cedpsych.2012.07.001

Braithwaite, D. W., Pyke, A. A., \& Siegler, R. S. (2017). A computational model of fraction arithmetic. Psychological Review, 124(5), 603-625. https://doi.org/10.1037/rev0000072

Bulgar, S. (2003) Children's' sense-making of division of fractions. Journal of Mathematical Behavior, 22(3), 319-334. https://doi.org/10.1016/S0732-3123(03)00024-5

Byrnes, J. P., \& Wasik, B. A. (1991). Role of conceptual knowledge in mathematical procedural learning. Developmental Psychology, 27(5), 777-786. https://doi.org/10.1037/0012-1649.27.5.777

Charalambous, C. Y. \& Pitta-Pantazi, D. (2007) Drawing on a theoretical model to study students' understandings of fractions. Educational Studies in Mathematics, 64(3), 293-316. https://doi.org/10.1007/s10649-006-9036-2 
Common Core State Standards Initiative (CCSSI). 2010. Common Core State Standards for Mathematics. Washington DC: National Governors Association Center for Best Practices and the Council of Chief State School Officers. Retrieved from http://www.corestandards.org/wp-content/uploads/ Math_Standards.pdf

Creswell, W. J. (2003). Research design: Qualitative, quantitative and mixed methods approaches (2nd ed.). London: Sage Publications.

Gabriel, F., Coché, F., Szucs, D., Carette, V., Rey, B., \& Content, A. (2013). A componential view of children's difficulties in learning fractions. Frontiers in Psychology, 4, 715. https://doi.org/10.3389/fpsyg .2013. 00715

Goldin, G. A. (2000). A scientific perspective on structure: task-based interviews in mathematics education research. In A. Kelly \& R. Lesh (Eds.), Handbook of research design in mathematics and science education (pp. 517-546). Mahwah, NJ: Lawrence Erlbaum Associates.

Hallett, D., Nunes, T., \& Bryant, P. (2010). Individual differences in conceptual and procedural knowledge when learning fractions. Journal of Educational Psychology, 102(2), 395-406. https://doi.org/10.1037/a0017486

Kerslake, D. (1986). Fractions: Children's strategies and errors. A report of the strategies and errors in secondary mathematics project. Windsor, England: NFER-Nelson.

Kieren, T. E. (1976). On the mathematical, cognitive, and instructional foundations of rational numbers. In R. A. Lesh \& D. A. Bradbard (Eds.), Number and Measurement. Papers from a Research Workshop (pp. 101-144). Columbus, OH: ERIC

Lacey, T. A., \& Wright, B. (2009). Occupational employment projections to 2018. Monthly Labor Review, 132(11), 82-123. Retrieved from https://www.bls.gov/opub/mlr/2009/11/art5full.pdf

Ma, L. (1999). Knowing and teaching elementary mathematics: Teachers' understanding of fundamental mathematics in China and the United States. Mahwah, NJ: Lawrence Erlbaum Associates.

Miles, M. B., \& Huberman, M. N. (1994). Qualitative data analysis: an expanded sourcebook. Thousand Oaks, CA: Sage.

National Council of Teachers of Mathematics [NCTM]. (2000). Curriculum and evaluation standards. Reston, VA: Author.

National Governors Association Center for Best Practices, \& Council of Chief State School Officers. (2010). Common Core State Standards for Mathematics. Retrieved from http://www.corestandards.org/Math/

National Science Board. (2010). Preparing the next generation of STEM innovators: Identifying and developing our nation's human capital. Retrieved from https://www.nsf.gov/nsb/publications/2010/nsb1033.pdf

Ritchie, S. J., \& Bates, T. C. (2013). Enduring links from childhood mathematics and reading achievement to adult socioeconomic status. Psychological Science, 24(7), $1301-1308$. https://doi.org/10.1177/0956797612466268

Rittle-Johnson, B., Siegler, R. S., \& Alibali, M. W. (2001). Developing conceptual understanding and procedural skill in mathematics: An iterative process. Journal of Educational Psychology, 93(2), 346 362. https://doi.org/10.1037//0022-0663.93.2.346

Siegler, R. S., Duncan, G. J., Davis-Kean, P. E., Duckworth, K., Claessens, A., Engel, M.,... Chen, M. (2012). Early predictors of high school mathematics achievement. Psychological Science, 23(10), 691- 697. https://doi.org/10.1177/0956797612440101

Siegler, R. S., Thompson, C., \& Schneider, M. (2011) An integrated theory of whole number and fractions development. Cognitive Psychology, 62(4), 273-296. https://doi.org/10.1016/j.cogpsych.2011.03.001

Stafylidou, S., \& Vosniadou, S. (2004) The development of students' understanding of the numerical value of fractions. Learning and Instruction, 14(5), 503-518. https://doi.org/10.1016/j.learninstruc.2004.06.015

Strauss, A., \& Corbin, J. (1990). Basics of qualitative research. London: Sage Publications Ltd.

Tirosh, D. (2000). Enhancing prospective teachers' knowledge of children's conceptions: the case of division of fractions. Journal for Research in Mathematics Education, 31(1), 5-25. https://doi.org/10.2307/7749817

Van Lehn, K. (1983). On the representation of procedures in repair theory. In H. P. Ginsburg (Ed.), The development of mathematical thinking (pp. 197-221). New York, NY: Academic Press.

Van Steenbrugge, H., Lesage, E., Valcke, M., \& Desoete, A. (2014). Preservice elementary school teachers' knowledge of fractions: a mirror of students' knowledge? Journal of Curriculum Studies, 46(1), 138161. https://doi.org/10.1080/00220272.2013.839003 
Wang, X. (2013). Why students choose STEM majors: Motivation, high school learning, and postsecondary context of support. American Educational Research Journal, 50(5), 1081-1121. https://doi.org/10.3102/0002831213488622

Yontz, E., Bossé, M. J., \& Sevier, J. (2018, Submitted).

http://www.iejme.com 